\title{
Characterization of Nuisance Particulates in the ISS: Space Smoke Aerosols and Lunar Dust Abatement
}

\author{
V. M. Bryg*, Z.-G. Yuan*, D. L. Urban**, G. A. Ruff**, G. Mulholland***, J. Agui** \\ *USRA/NCSER at NASA Glenn, MS110-3, 21000 Brookpark Rd., Cleveland, OH 44135 \\ ** NASA Glenn Research Center, 21000 Brookpark Rd., Cleveland, OH 44135 \\ ***The University of Maryland, University Park. Md.
}

Fire detection equipment has always been important for spacecraft fire safety. Currently an experiment Smoke Aerosol Measurement Experiment_R (SAME_R) is underway for the International Space Station ISS which generates smoke from the combustion of common materials that have been selected as space flight hazards. Because of the difference in the particle size of aerosols generated by the combustion of common materials, spacecraft smoke detectors must detect different types of smoke. This requires an understanding of the size, mass and type of airborne particles expected to be generated by a fire on a spacecraft. Instruments used on other spacecraft include near-IR forward scattering detectors, ionization detectors, and the Skylab module used UV-sensing fire detectors.[1]

SAME_R will assess the size and distribution of smoke particles produced by different types of material found on spacecraft such as Teflon, Kapton, cellulose and silicone rubber. It is known from previous experiments that smoke aerosol particles generated from low gravity flames can be larger than those generated by fires on earth.[2] A thermal precipitator is used to collect the material aerosols which are then measured using various highly sophisticated instruments. To ensure the validity of these measurements, an actual measurement of the aerosol or smoke particles as deposited on TEM grids will be made. Figures 1 features TEM images of smoke particles from lampwick (cellulose) and Teflon.

Another potential safety hazard is the presence of lunar or planetary dust brought onto the spacecraft following exploration of the surfaces. The mitigation of this dust is also a safety consideration. It is necessary to develop methods to prevent inhalation of tiny charged particulates $(<10 \mu \mathrm{m})$. The dust is also a nuisance in that it adheres tenaciously to surfaces causing abrasion of important equipment such as spacesuit seals, faceplates and instrumentation.

The Lunar Dust Filtration Testing Facility at NASA Glenn is employed in the characterization of the filters of some lunar regolith particles, e.g., JSC-1A, a lunar simulant.[3] SEM and TEM images illustrate the shape and size of the simulant particles and SEM is being used to characterize the different filters from the Testing Facility (Figure 2). Calibrated $\mathrm{SiO}_{2}$ particles of varying sizes and shapes have been characterized along with a number of filters which will be instrumental in determining the best filtration system to employ for the protection of the crew's health, spacecraft instrumentation, and materials.

[1] Friedman, R., "Fire Safety Practices and Needs in Human-Crew Spacecraft," Journal of Applied Fire Science, Vol. 2, 1992, pp. 243-259.

[2] Bukowski, R. W., et al., "Performance of Home Smoke Alarms, Analysis of the Response of Several Available Technologies in Residential Fire Settings," NIST Technical Note 1455, December 2003. 
[3] Agui, J. A. and Mackey, J "Development and Testing of a New NASA Lunar dust Filtration Testing Facility,” SAE International Conference On Environmental Systems, July 2009.
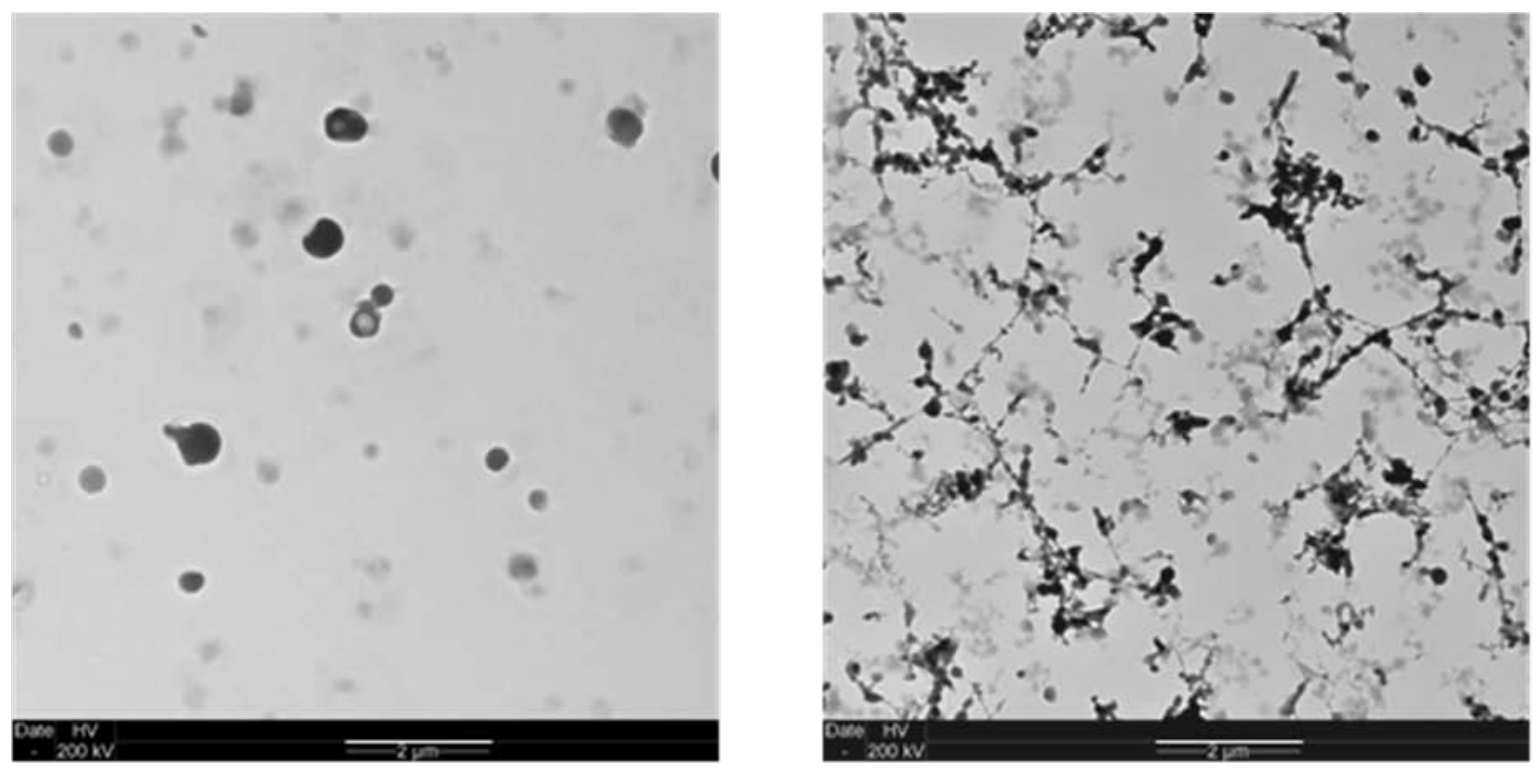

$$
\mathrm{bar}=2 \mu \mathrm{m}
$$

Figure 1. Typical TEM photomicrographs of lampwick (cellulose) and Teflon particles

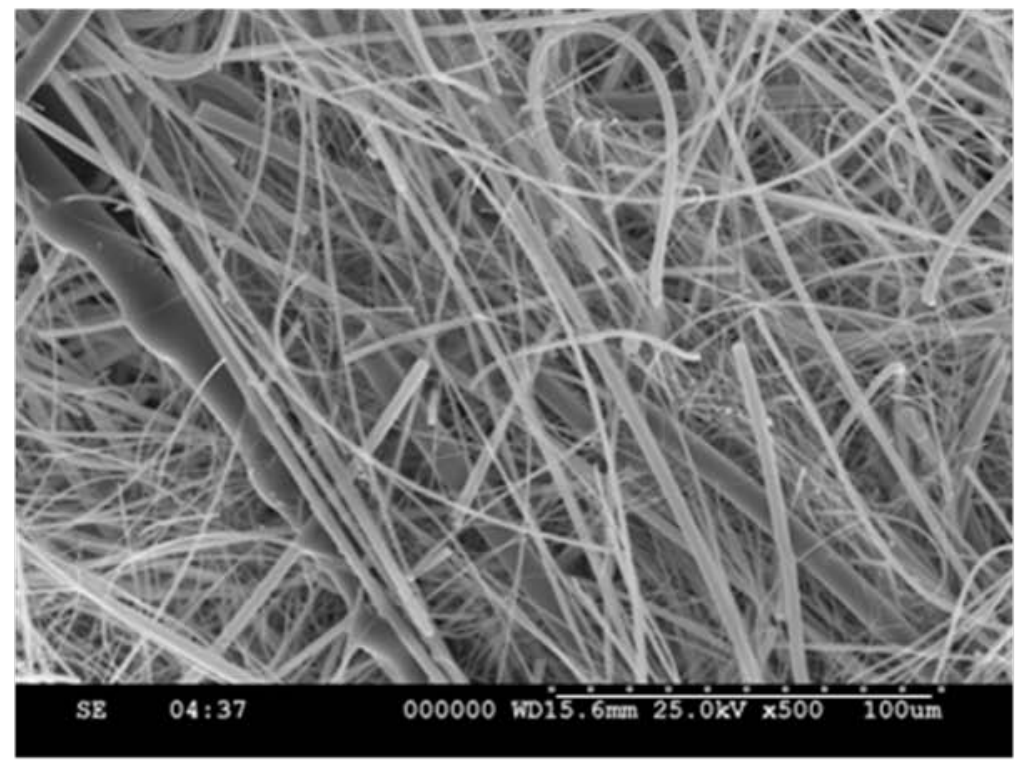

$$
\text { bar }=100 \mu \mathrm{m}
$$

Figure 2. SEM of an candidate glass filter for simulant filtration. 